\title{
Plastic Fiber Optics Embedded in Concrete (to study its Light-Transmitting Properties) for Sustainable and Economical Buildings
}

\author{
Caroline A. Sobo ${ }^{1 a}$, Sadia Farooq ${ }^{2}$, Salman Azhar ${ }^{1 b}$ \\ RECEIVED ON 07.01.2020, ACCEPTED ON 15.09.2020
}

\begin{abstract}
Concrete, a material that can be used as a building material and at the same time when mixed with light source, can enhance the beauty of a space as well as open new ways to experiment with it. The vision behind the research is to contribute with the manufacturers who are having "vision of cities that glow from within" through the use of concrete embedded with optic fiber strands. The aim of this research is to determine light transmitting properties of translucent concrete embedded with plastic fiber optics. In this experimental study, the amount of light is calculated that is able to transmit through the concrete. The four concrete blocks of equal size but different in amounts of plastic fiber optic strands are made. The research concluded that the fiber optics has the good light guiding properties which allow light to pass through the concrete in sufficient amount. The concrete with plastic fiber optics is named as translucent concrete, provides endless varieties of applications, not only aesthetically pleasing, but it can also promote safety, privacy and security as well as integrate the idea of saving green energy in the construction industry.
\end{abstract}

Keywords: Plastic Fiber Optics, Embedded, Concrete, Light-Transmitting Properties, Sustainable, Economical Buildings

\section{INTRODUCTION}

$\mathrm{C}$ oncrete is a widespread popular building material because of its economic value, practical uses and structural properties. The term concrete is being used to describe "mortar". Bernard Forest in his book named Architecture Hydraulique [15] first time writes it as concrete. The only defect is its dull rough surface, but in last fifteen years the contemporary technology has opened new advancements in this material, now it can be stained, polished, or etched to make it look good i.e. stones, marble, pavers, etc. The concrete can be embedded with various aggregates to alter its strength and tensile properties and it can even be categorized as a green building or sustainable material when made with recycled aggregates such as crushed recycled glass.

The concrete is being used for innovations to increase its usages through experimentation, just like an idea generated to embed plastic fiber optic strands into concrete to make it translucent. The translucent concrete is a solid state of concrete with light transmitting properties [7]. Optical fibers are used because of their material composition to pass the light and to bounce it from one end of the stone to the other, effectively preventing the loss of light traveling through the fiber optic as it transmits light [7]. The end result is a light pattern that depicts the fiber structure on the other surface. The new product "translucent concrete" is functional which can be utilized for safety

\footnotetext{
${ }^{1}$ McWhorter School of Building Science, Auburn University, USA. Email: a amsam07@gmail.com,

bsalman@auburn.edu

${ }^{2}$ Department of Interior Design, University of Home Economics, Lahore, Pakistan. Email: drsadiafarooq@uhe.edu.pk (Corresponding Author).
}

This is an open access article published by Mehran University of Engineering and Technology, Jamshoro under CC BY 4.0 International License. 
monitoring, environmental protection, energy saving and artistic modeling [6].

Although, translucent concrete has been considered mostly for the decorating purpose in interior, but the manufacturers "have visions of cities that glow from within, and buildings whose windows need not be flat, rectangular panes, but can be arbitrary regions of transparency within flowing, curving walls" [1]. It has flexibility to be used in numerous places e.g. structural material and illuminating source $(3,13]$. As concrete has ability of insulating indoors from extreme weathers so translucent concrete is best for dual functioning, one for insulating and second letting in daylight [9]. According to International Energy Agency [10], the office buildings are consuming about $30 \%$ to $40 \%$ of the electricity from total of $19 \%$ of the total electricity which is being used in all buildings." Even more, lighting fixtures in commercial buildings increase the expense three times the energy of air conditioning and are responsible for consuming more electrical energy than anything else [1]. When building is constructed with the intention of lowering energy, power consumption and costs, it comes under sustainable movement. Translucent concrete can be used to allow sunlight to penetrate the walls of the building. This in turn utilizes natural light as a light source to illuminate the interior of the building. In using this material, artificial lighting will not always be necessary, ultimately saving valuable resources and money. The innumerable opportunities of translucent concrete expand its vision to be used as both building material and light source [12]. Current applications of this material include use on the areas like floors, pavements, walls, partitions, fixtures, furniture and even facades for the decorative and aesthetic purpose [9].

\section{LITERATURE REVIEW}

\subsection{Concrete:}

A Material both Stigmatized and Celebrated "Stigmatized on one hand and celebrated on the other" [11] concrete as a building material evokes highly diverse reactions among its consumers and, due to this, has managed to convey inconsistent associations. For some, these inconsistencies like its poor colour, or rough texture have caused the use of concrete as a building material to be misunderstood, disliked and underappreciated. Additionally, the rapid urbanization of the 1960's, which led to a boom in concrete consumption and use, has caused today's consumers to view the material as dated, boring and undesirable. While many have come to view concrete as a lackluster building material, others view it as a strong, long lasting material which has capability to merge or mixed with other materials to raise its usages in daily life [13] The use of concrete mixture which simply consists of cement, sand and water, can be utilized with addition of new materials to generate innovative products, one of which is translucent concrete. If implemented into the construction industry as a building material, translucent concrete can have many applications, including sustainability, insulation, safety and much more.

\subsection{Translucent Concrete}

Preceding the idea that a translucent material could be achieved by adding large amounts of glass in concrete, Hungarian architect Aron Losonczi first developed the concept of translucent concrete in 2001 at the Technical University of Budapest [15] and in 2003, Losonczi developed pre- fabricated translucent concrete blocks, which he called LiTraCon (a pseudonym or light transmitting concrete") (Table 1). This new material presented the ideas for a wide variety of its applications as a new material for construction and decoration. The concept of light transmitting concrete is permitting interaction between the nature and buildings, and the creation of illuminated materials $[11,15,19]$.

Losonczi's successful implementation of prefabricated translucent concrete blocks into the construction industry quickly inspired other builders also to experiment with this unique material. Intrigued by Losonczi's product and in hopes to take it further, Joel S. and Sergio O.G. eventually went on to develop a transparent concrete material, which allowed $80 \%$ light to transmit through and is only $30 \%$ the weight of standard concrete [6]. 


\begin{tabular}{|l|l|}
\hline \multicolumn{2}{|c|}{$\begin{array}{r}\text { Table 1: Properties of Transparent Concrete } \\
\text { Blocks by Litracon Company }\end{array}$} \\
\hline \multicolumn{1}{|c|}{ Shape } & \multicolumn{1}{c|}{ Prefabricated blocks } \\
\hline Materials & $96 \%$ concrete, $4 \%$ optic \\
\hline Density & $2100-2400 \mathrm{Kg} / \mathrm{m}^{2}$ \\
\hline Block Sizes & $\begin{array}{c}600 \mathrm{~mm}-300 \mathrm{~mm} \\
(23.62 "-11.81 ”)\end{array}$ \\
\hline Thickness & $25-500 \mathrm{~mm}$ \\
\hline Colour & White, Grey or Block \\
\hline Fiber Distribution & Organic \\
\hline Finishing & Polished \\
\hline Compressive Strength & $50 \mathrm{~N} / \mathrm{mm}^{2}$ \\
\hline $\begin{array}{l}\text { Bending Tensile } \\
\text { Strength }\end{array}$ & $7 \mathrm{~N} / \mathrm{mm}^{2}$ \\
\hline
\end{tabular}

Reference: [6]

Translucent concrete is made from the fine-grain concrete and fiber optics. When cast into the concrete, the light comes out from the holes which are made between the sides of the blocks. When light enters the fiber optic strands on one side of the block, the lightguiding properties of the fiber optic allow the light to travel along the inside of the fiber until it eventually reaches the end and exits through the other side. The strength of the concrete remains almost the same because the fibre optics mix well with the concrete $[3,6]$.

\subsection{Translucent Concrete:}

Manufacturing Process The mechanism of making translucent concrete is just like traditional concrete, except that optical fibers are embedded into the mixture of cement. However, the mixture for concrete consists of fine material rather than the coarse aggregate. After the concrete is mixed, the mixture is spread in the form of concrete layers on one and another, including the fibers [19]. It can be available as a pre manufactures concrete block and panels. The final product is a new type of material which is homogeneous from inside and outside. The thousands of strands of optical fibers (usually equaling $4-5 \%$ of the concrete volume) are cast into the concrete to transmit light, either natural or artificial [16].

The previous methods were time consuming and costly because of individually adding fiber filaments into the concrete. But now a days, the single filament is not being used and instead of it semi manufactured woven fiber fabric is in hand to use [12]. These automatically imposed woven fabrics increase productivity when it comes to pre-casting translucent concrete blocks. This process allows fabric and concrete to be inserted alternately into molds at intervals of approximately $2 \mu \mathrm{m}$ to $5 \mathrm{~mm}$ [16]. While the thin, lean fabric increase the quantity of light to pass through the concrete, the addition of optical fibers do not hinder the compressive strength of the concrete. The material is cut into blocks or panels as required according to the specified or required thickness which can be polished, with high gloss or semi-gloss [6]. There is not a big international market of manufacturers for translucent concrete but a few like LitraCon, Lucon and Lucem Lichbeton. Litracon have given a price of $\$ 1000 / \mathrm{m} 2$ for $25 \mathrm{~mm}$ thickness for the translucent concrete [7].

\subsection{Translucent Concrete: Materials}

The two main materials which are essential to process for translucent concrete are the simple concrete and fiber optics. The advantages of these two materials are combined to develop a novel functional material which is valuable in the field of construction. In addition to the two basic materials, other raw and secondary materials can be used in the production of translucent concrete, including Portland cement, aggregates (such as crushed stone or gravel water), and of course, the fiber optic strands [13].

\subsection{Translucent Concrete: Optical Fibers}

To create translucent concrete, the optic fibers are mixed into concrete to transmit or throw light and it can be shaped as desired, making it a material that differs from other concrete building materials [15]. The fibers are mixed into the concrete with its traditional components- water, sand and cement; this causes the optic fibers to form a matrix and placed at the parallel distance along the concrete, it can transmit light between the two surfaces of the concrete in which they are embedded. The fiber optic strands, are almost $5 \%$ of the total translucent concrete with the quality to reflect light. Once cured, the optical fibers allow sunlight to penetrate the concrete, forming shadows 
and sharp outlines on both sides, inside and outside of the structure $[16,17,20]$.

Optical Fibers do not conduct energy, but rather work as a cylindrical waveguide that transmits light along its axis. Pure optical glass or plastic (the material used to make the fibers) differs from other types of glass in that it has few impurities [13]. This in turn gives it a better light transmitting property, causing optic fibers to transmit light so efficiently and there is almost no loss of light through the fibers [15]. As seen in Fig. 1, the basic structure of an optical fiber consists of three parts: the core, the cladding, and the coating or buffer. The core is a cylindrical rod made of dielectric material [15]. A layer of material called the cladding surrounds the core, and, like the core, it is made of a electric material.
It can be useful for a number of functions such as it reduces loss of light from the core into the surrounding air, reduces scattering loss at the surface of the core, protects the fiber from absorbing surface contaminants and adds mechanical strength [5].

For further protection, an additional layer called the coating or buffer fortifies the cladding, and, because it is elastic in nature, it protects the optical fiber from physical damage by preventing abrasions [5]. The buffer also prevents the optical fiber from scattering losses caused by micro-bends, which occur when an optical fiber is placed on a rough and distorted surface [5]. As seen in Fig. 1 and 2, the light in a fiber optic cable travels through the core by constantly bouncing off the cladding, a principle called total internal reflection [13].
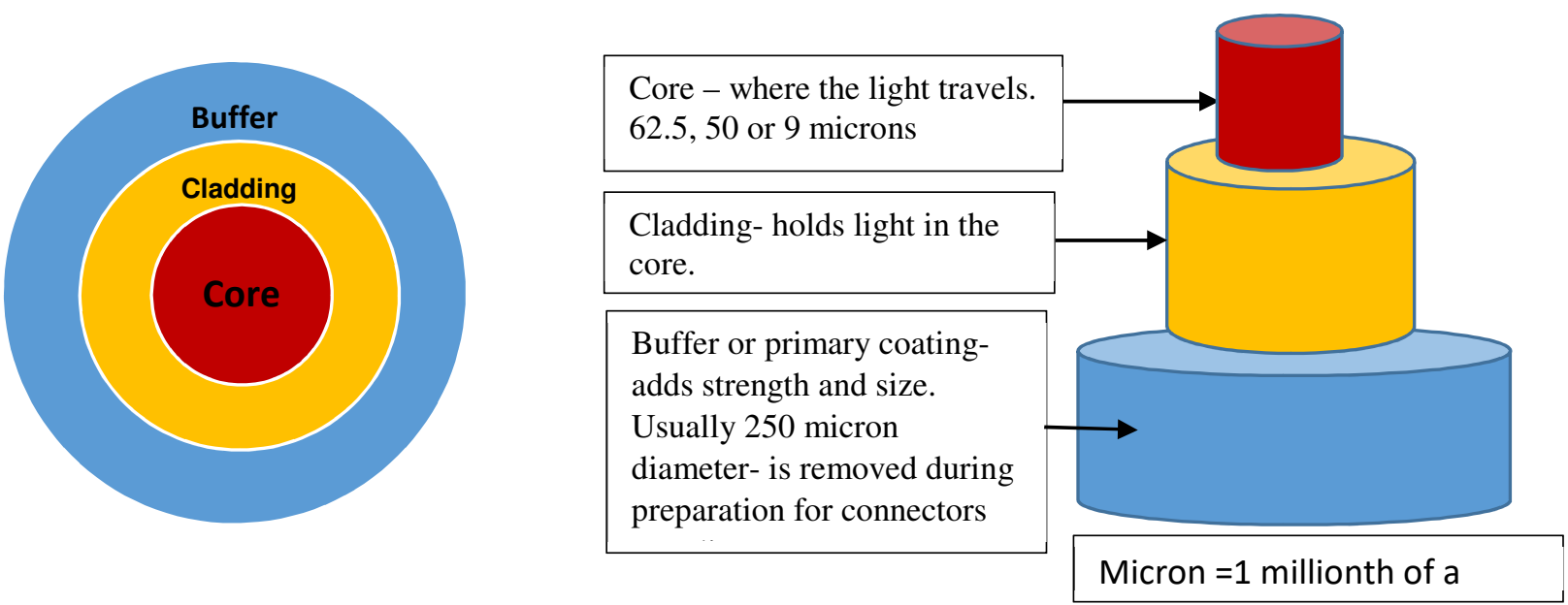

Fig. 1: Structure of an Optical Fiber

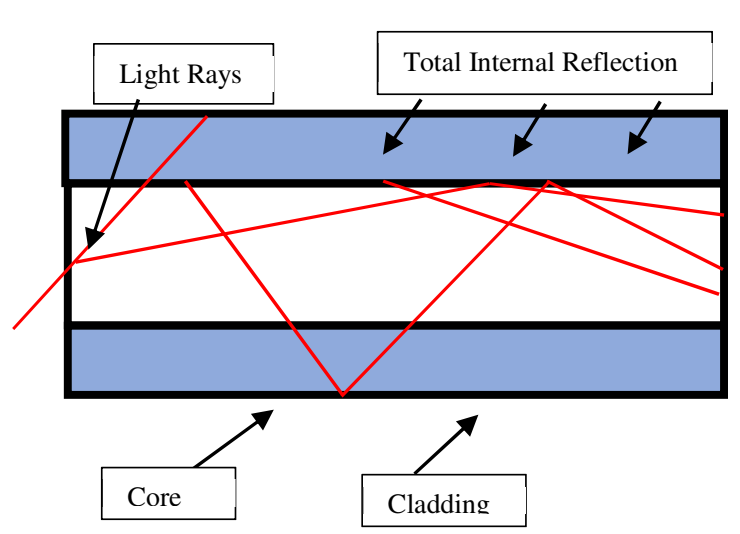

Fig. 2: Illustration of Total Internal Reflection

\subsection{Translucent Concrete: How is it used?}

Featured in the "Liquid Stone" exhibit at the National Building Museum in 2006, translucent concrete not only opened peoples' eyes to all kinds of possibilities, but has also prompted companies to experiment with and use the material to create their own products.

While the material has definite architectural and interior design application, a few companies are working with light-transmitting concrete with exclusive practical applications. The translucent concrete was being used for interior decoration but

Mehran University Research Journal of Engineering and Technology, Vol. 40, No. 2, April 2021 [p-ISSN: 0254-7821, e-ISSN: 2413-7219] 
designers have the insight of the cities that shine through buildings, then the windows or panes will not be required to transmit light inside but the structure will allow the light to pass through and illuminate the inner sides of the rooms [12].

Currently, the translucent concrete is produced in a limited quantity because the process is low tech and slow. The other reason is the pre-cast or prefabricated blocks and panels and is not easy to be constructed at the place as the traditional concrete [12]. While these disadvantages are major contributors as to not being produced in a huge quantity, the light transmitting feature of the material has earned it a reputation of being innovative, problem-solving and versatile. The new horizon would open in front of the world to change the structural and decorative needs in shape of the optic materials [19]. The translucent concrete has the great ability to transform concrete buildings, turning them from a drab, dull and depressing material associated with closed dark box, office buildings, basements with coarse finish and rough surface patios, to a material that can alter the interior of concrete buildings and giving them opportunity to look wide, spacious and fresh [8].

The product's unique and versatile properties have made it a material with endless possibilities. While it has been used for several applications already, there are many emerging trends that have developed as a result of experimentation. Some of these applications include conventional uses such as translucent blocks suitable for floors, pavements and load-bearing walls. The panels are suitable for facades, cladding and dividers. The emerging uses or trends include partitions in the form of walls to access for natural sunlight, in furniture for the decorative and aesthetic uses. the other uses are light fixtures, pedestrians, stairs, decorative tiles etc. [4].

\subsection{Translucent Concrete: Current Applications}

The Litracon is producing blocks in various sizes, for providing options to the builders and designers. The illuminating blocks are also being used in the furniture items to the huge decorative facades [12]. The possibilities to work with the translucent concrete are numberless. The translucent concrete was used as a major component in a building in 2010 at Shanghai World Expo, whereas Italy displayed a pavilion that was designed and built using translucent concrete blocks $[14,18]$. The translucent blocks of concrete were adjoined with opaque blocks to create a façade to glow at night time $[14,18]$. This mix of translucent and opaque concrete blocks surrounds the windows in the center of the building allowing natural light into the structure. Located at the public entrance of Fortress Monostor in the Hungarian town of Komarom, "The Europe Gate" was "designed to mark the celebration of Hungary joining the European Union (EU)" [7]. Standing at 36.7 feet tall, it is considered one of the largest artistic installations using this novel material. Losonzci, the architect and builder of this gate, utilized his recently developed material [18] to combine optical lighting display and artistic influence, ultimately portraying and celebrating an important moment in history for his country [7]. While the structure is illuminated by the sun in the mornings and late afternoons, it offers a much more impressive view at night when the embedded plastic fiber optics lights it from the inside. As translucent concrete gained more popularity, certain developers from around the world began commissioning it for a variety of applications. Litracon has also used it for the first public square in Stockholm, Sweden. In the day time the square's sidewalk was made up with conventional concrete but the colored lights were installed beneath the surface which glow at night time [8]. These sidewalks are beneficial to the people of the city because they aid in visibility, especially during dark hours. In lighting sidewalks from underneath, pedestrians have greater ease going outdoors at night as they can see their path simply by glancing down. Finished in 2011, Bank of Georgia headquarters in Eastern Europe utilized this material throughout the interior of their building when it was renovated. The structural features of almost 300 square meters $(3,229$ square feet) of translucent concrete were made by German manufacturer LUCEM, including LED-lit wall panels [8]. The use of LED fiber optics within the building serves several purposes, including the enhancement of security while providing privacy as well as interior decorative purposes. Recently, the Italian Ambassador claimed that translucent concrete is to be used in several 
buildings at the new Italian Embassy in Bangkok [4, 14, 18]. If translucent concrete is used for this building, it will be the second major building constructed with this material.

\subsection{Translucent Concrete: Sustainable Material}

Described as the new innovative constructional material which can be said as green material [12], many people not only see light-transmitting concrete as a solution for maximizing the amount of natural lighting within buildings, but can also be used for getting more light into the building at night time [12]. It can be said as a green material because it can help in reducing the high input for electricity and high output of pollution, it can be an energy saving technology [4, 17]. The illumination inside the rooms is essential to maintain for which artificial light is being used at a high cost [17]. Many sustainable organizations specify certain requirements to be met by a building in order to earn any kind of sustainable certification. For example, the Indian Green Building Council (IGBC) requires $50 \%$ of the light illuminating the interior of a green building to be natural daylight.

Translucent concrete permits sunlight to be used as a light source when we are using electricity in rooms even at daytime. The necessity to use artificial light diminishes and fewer lights are required during daylight hours, making the reduction of power consumption possible, when a dark solid wall is replaced with illuminating wall. Especially, when the other qualities of a wall remain unchanged like insulation, cover and safety [12].

Due to its light-transmitting properties, buildings can use sunlight as a source of light instead of electricity, ultimately reducing the amount of artificial light needed to meet the buildings demand for illumination [4].

\subsection{Translucent Concrete: Aesthetic Material}

In addition to a sustainable material, translucent concrete has been utilized to achieve aesthetic products. Even though traditional concrete has been seen as a dull and unexciting material, it has been brought to the consumer's attention that the concrete is not only the material with a grey dull look but revolutionary, it has changed its style and output to look beautiful and aesthetical and to use as green material [18]. Aesthetic applications of translucent concrete include the following:

\section{Illuminate Walls}

Transparent concrete can be utilized both interior and exterior walls. Eastern or western placement is recommended if natural sun is desired to penetrate into a given area; the rays of the rising or setting sun will hit the optical fibers in a lower angle, providing a more direct (and therefor intense) light. German company and one of the original manufacturers of the material, LUCEM, erected the first LED infused concrete wall. The wall displayed 136 color-changing concrete panels which can be used as bill boards for advertisements and displays. The material can allow sunlight to pass through the bedroom and into the bathroom during the day, and lighting from the bathroom to illuminate the bedroom at night.

\section{Benches}

Benches can be built using translucent concrete. This not only gives the bench a uniquely decorative and intriguing presence, but also promotes safety and security for the user if used in a public area at night [2, 4].

\section{Lighting Fixtures}

Lighting fixtures have been created to add an interesting aesthetic piece to room décor. When lit from the inside, the optical fibers not only allow light to penetrate through, but they can also project specific patterns onto the walls, ceiling and floor of the surrounding area, creating an even more attentiongrabbing feature.

\section{Bar Tops}

When embedded with plastic fiber optics and hooked up to an LED light source, a bar top embedded with LED plastic fiber optics can become an interesting focal point in a bar, restaurant or even in a home. 


\section{Logos}

When arranged in a specific pattern, the fiber optics can draw on either LED lights or natural light to present a $\log$ o on a building, sign, or any surface. LLUCEM, a German manufacturer of translucent concrete (the company that produced the previously stated LED infused wall), used transparent concrete as well as fiber optic technology to portray their logo on the side of their office building. Not only does this draw people in as the innovative building material sparks curiosity, but it also provides an example of their product and serves as an advertisement of the type of work they do.

\section{Reception Desks}

To create a look that stands out, translucent concrete can be used to light reception desks on the top and front $[2,14,18]$. This not only creates a focal point in a room, but also draws customer's eyes to the desk area, indirectly providing them with direction.

\subsection{Translucent Concrete: Safety Material Light sidewalks at night (from within)}

Not only would it add uniqueness to an area, but it would also promote safety and security, encouraging foot travel during darker hours. If pedestrians feel safe, they will be more willing to travel at night. This is beneficial because it boosts an area's visual appearance, as well as enhances the happiness and therefor well-being of the people.

\section{Increase visibility in dark subway stations}

Translucent concrete can be utilized in the construction of underground areas such as subway stations. If used, it would allow natural light to penetrate through the ground and into the stations, increasing visibility. Increased visibility in subway stations is also theorized to have a domino effect, leading to more travel, less loitering and crime, and ultimately nicer public facilities and transportation.

\section{Doors/Walls}

The material can be utilized on front doors and walls to see the outside person standing on our doorstep.
Establishments such as schools, museums, and prisons can find translucent concrete walls functional as they add safety as well as security and improve supervision.

\section{Illuminating speed bumps in parking lots and on roadways at night}

Speed bumps in parking lots and on roads can use translucent concrete blocks with a light source beneath to aid in visibility and safety while driving in the dark. Even road constructing companies can use this material to light up the roads, aiding drivers in staying alert and aware of their surroundings [6].

\subsection{Summary of Literature}

A novel architectural material, translucent concrete is considered to be one of the most interesting new material on the historically old and uninspiring list of building materials. Combining the opaque and transparent quality of concrete mix with glass or plastics can allow light to penetrate inside it and it can also provide privacy and structural strength $[6,12]$. While its drawbacks include high cost and long manufacturing time, its great potential to serve a multitude of applications make it highly advantageous. Developed by embedding optical fibers into a concrete mixture, translucent concrete can be used almost anywhere that glass or traditional concrete is used [12]. The material has good light guiding property, making the ratio of optical fiber volume to concrete proportionate to transmission of light. Translucent concrete has exciting vital properties that improve and enhance a building's appearance. Used where light cannot reach with appropriate intensity, this new kind of building material can integrate the ideals of energy saving with the usage of self-sensing properties of functional materials. The concrete is used widely in architecture and can have a vast possibility of alterations in upcoming years.

\section{METHOD \& EXPERIMENTATION}

\subsection{Experimental Design}

The four equal concrete blocks were made with different amounts of light to pass through by adding 
different amount of plastic fiber optic strands. A fundamental concept of the mold, illustrating how it will be divided into four equal size sections as well as how the fibers will be threaded uniformly through the face of each block is shown in Fig. 3. All the required material was collected before conducting the experiment (Table 2).

\begin{tabular}{|ll|ll|}
\hline \multicolumn{4}{|c|}{ Table 2: Materials used during the Experiment } \\
\hline$\bullet$ & 2 bags of Quikrete & $\bullet$ & Towel \\
\hline$\bullet$ & Fiber Optic Cables & $\bullet$ & Permanent Marker \\
\hline$\bullet$ & Measuring Tape & $\bullet$ & Light Sensor \\
\hline$\bullet$ & Drill & $\bullet$ & Flashlight \\
\hline$\bullet$ & Screws & $\bullet$ & Saw \\
\hline$\bullet$ & Wood & $\bullet$ & Bucket \\
\hline$\bullet$ & Drill Bit & $\bullet$ & Scissors \\
\hline$\bullet$ & Water & $\bullet$ & \\
\hline
\end{tabular}
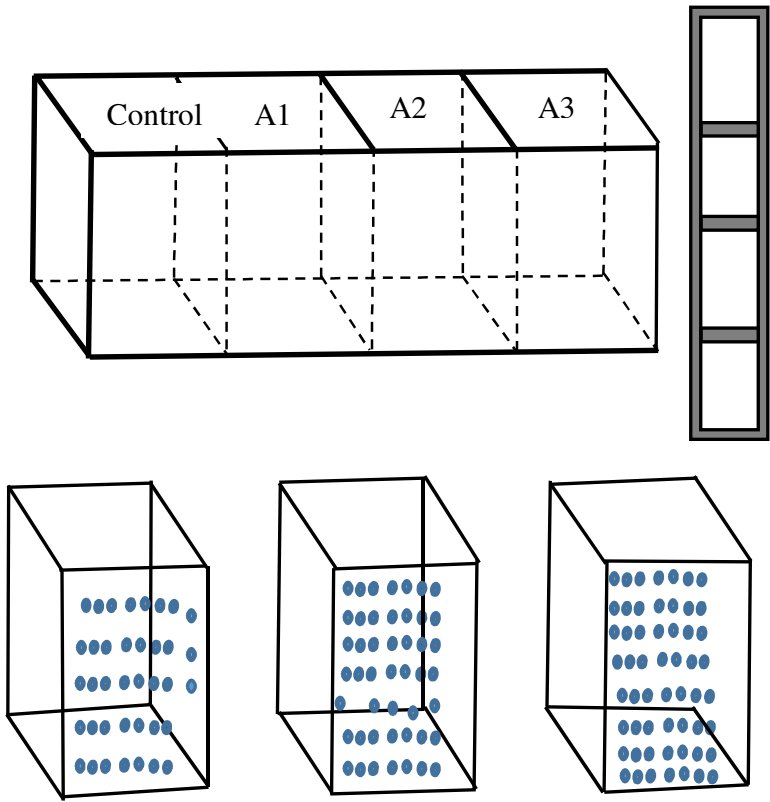

Fig. 3: Capstone Notes- Illustration of Mold

\subsection{Build Mold}

One large mold was designed and built using $2 \times 4$ lumber, screws and a drill (Fig. 4). Then, the inside of the mold was measured length wise and divided by 4 to figure where the dividers would go within the mold. As seen in Fig. 5, the mold was marked where the dividers would go to provide direction as well as ensure spacing was even before inserting the dividing pieces of wood.

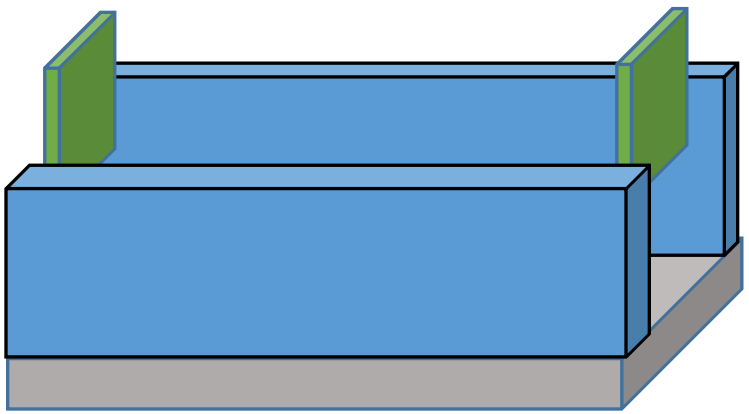

Fig. 4: Capstone Notes - Illustration of the mold structure

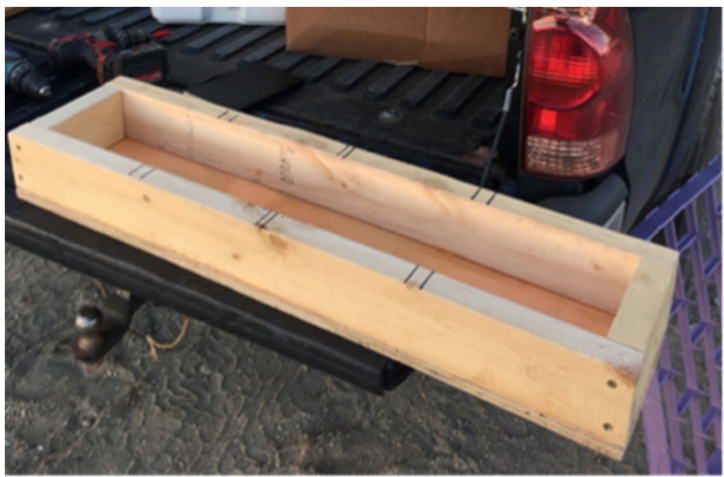

Fig. 5: The main structure of the mold before dividers were added

Once the main structure of the mold was built, three dividers were cut (also using 2x4's) and placed within the directive markings on the mold. They were then secured, creating even intervals within the large mold for the four blocks of concrete.

Each block was labeled for identification: block A served as the control and had zero optical fibers embedded within it, A1 had 5\% surface volume of optical fibers, A2 had 10\% surface volume, and A3 had 15\% surface volume (Reference Table 3 and Fig. 6 for results).

Once the mold was built and each unit was labeled, the number of fiber optic strands that would be embedded into each concrete block was calculated. To determine this, the surface area of the side of the block to be penetrated by the fibers was calculated. After the surface area was calculated, it was multiplied by each block's respective percentage of fiber optics. That result was then converted to $\mathrm{mm} 2$ from in 2 to make it calculable with the fiber optics (which are measured in $\mathrm{mm})$. Lastly, the square root of that number was taken 
to know how many milli meters were required to determine how many fibers were required to make up their respective surface area percentage.

\begin{tabular}{|l|c|c|c|c|}
\hline \multicolumn{5}{|c|}{ Table 3: Number of fiber optics to be embedded in } \\
each concrete block \\
\hline $\begin{array}{l}\text { Number } \\
\text { of Fiber }\end{array}$ & $\begin{array}{c}\mathrm{A} \\
(0 \%)\end{array}$ & $\begin{array}{c}\text { A1 } \\
(5 \%)\end{array}$ & $\begin{array}{c}\text { A2 } \\
(10 \%)\end{array}$ & $\begin{array}{c}\text { A3 } \\
(15 \%)\end{array}$ \\
\cline { 2 - 5 } Optics & 0 & 33 & 47 & 58 \\
\hline
\end{tabular}

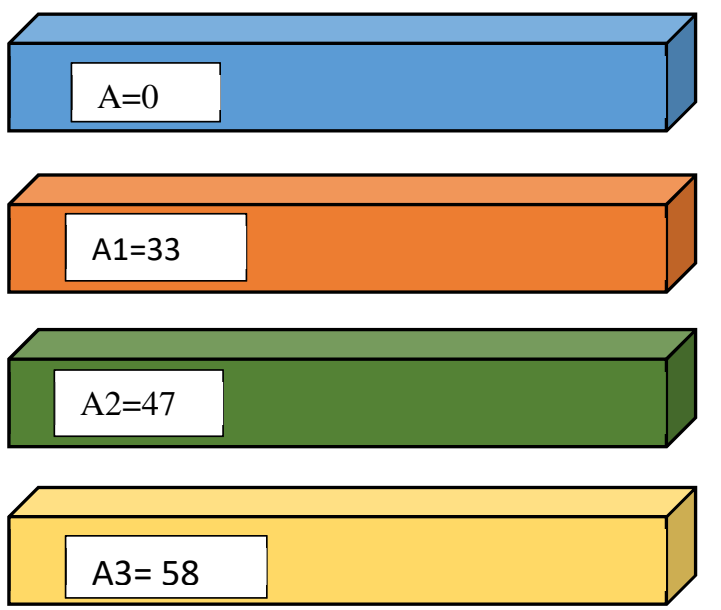

Fig. 6: Notes - Calculations determining the surface area of each block and number of fiber optic strands required for each block

The calculations are given below to calculate the number of fiber optics in each concrete block with fiber optical surface volume:
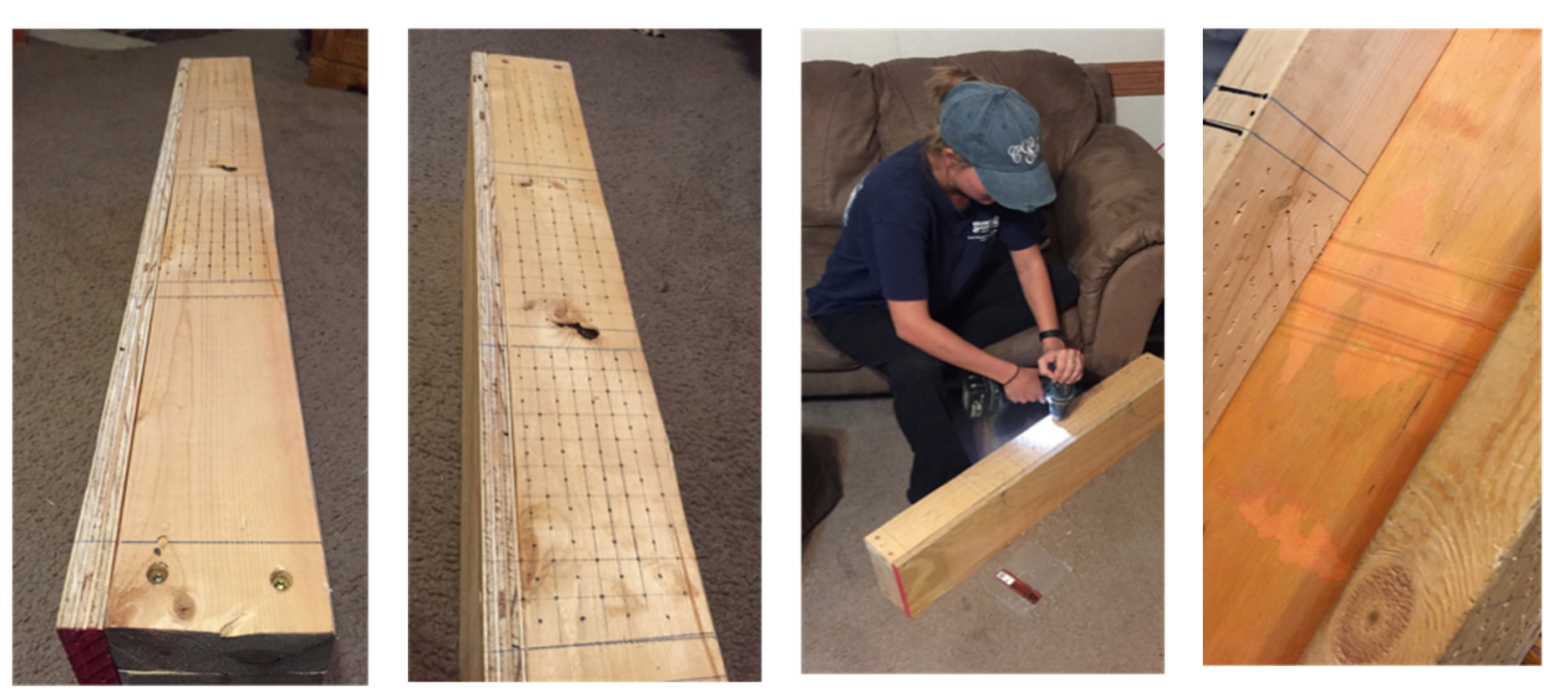

Fig. 7: Process of Marking, Drilling, and Stringing the Fiber Optics through the Mold

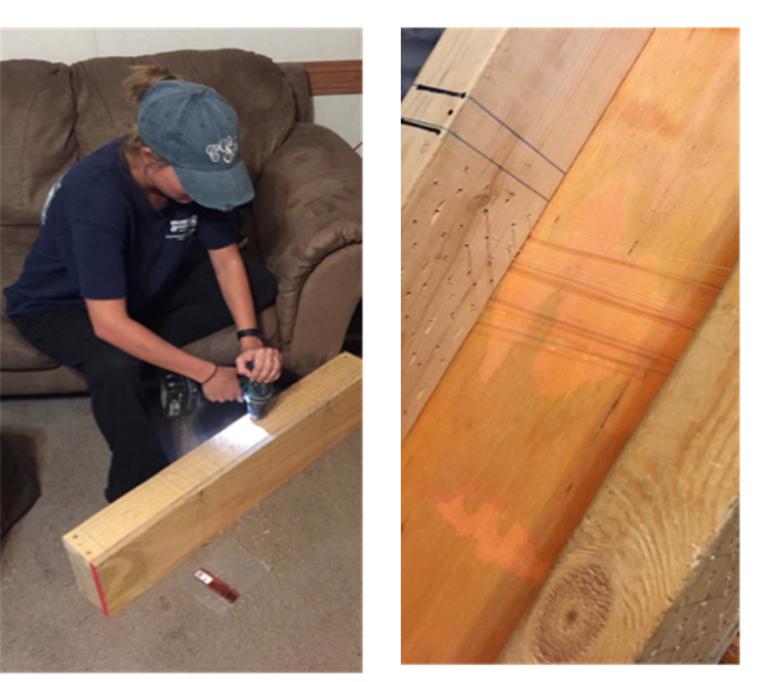

\section{Fiber optical surface volume $=0.75 \mathrm{~mm}$}

Surface volume of sides $=7.7$ " $x$ 4.5" $=34.65 \mathrm{Sq}$. in

$1 \mathrm{Sq}$. in = 645.16 Sq. $\mathrm{mm}$

A1) $5 \%$ of $34.65 \mathrm{Sq}$ in $=\frac{34.65 \times 5}{100}=1.7325 \mathrm{Sq}$. in $=$ $1.7325 \mathrm{Sq}$ in $\mathrm{x} 645.16 \mathrm{Sq} \mathrm{mm}$

$=1117.7397 \mathrm{Sq} \mathrm{mm}=\sqrt{1117.7397 \mathrm{Sq} \mathrm{mm}}$ $=33.4326 \mathrm{~mm}=33$ fiber

A2) $10 \%$ of $34.65 \mathrm{Sq}$ in $=\frac{34.65 \times 10}{100}=3.465 \mathrm{Sq}$. in $=$ $3.465 \mathrm{Sq}$ in $\mathrm{x}$ 645.16 $\mathrm{Sq} \mathrm{mm}=2235.45794 \mathrm{Sq} \mathrm{mm}$ $=\sqrt{2235.45794 \mathrm{Sq} \mathrm{mm}}=47.28 \mathrm{~mm}=47$ fiber

A3) $5 \%$ of $34.65 \mathrm{Sq}$ in $=\frac{34.65 \times 15}{100}=5.1975 \mathrm{Sq}$. in $=$ $5.1975 \mathrm{Sq}$ in $\mathrm{x} 645.16 \mathrm{Sq} \mathrm{mm}=3353.2191 \mathrm{Sq} \mathrm{mm}=$ $\sqrt{3353.2191 \mathrm{Sq} \mathrm{mm}}=57.9063 \mathrm{~mm}=58$ fiber.

Once the number of fiber optics strands required for each block was calculated, the location at which each one would pass through the forms was measured and marked for drilling (Fig. 7). To ensure uniformity, it was decided that the fiber optics would be placed in an even pattern across each mold. It is important to note that these holes were measured out on both sides of the mold so the fiber optics could pass through in an even, parallel fashion. Once all holes were drilled, the fiber optics were individually strung through one side of the mold and led out of the corresponding hole on the other side, and then fastened to both sides (by either tape or tying). Once all plastic fiber optics had been strung through the mold and fastened, the mold was ready for concrete. 


\subsection{Mix and Pour Concrete}

Concrete was mixed and poured at General Contractor Rabren Construction's Auburn High School addition site. While the concrete Rabren was using to pour their foundations was going to be used for this experiment, it was quickly determined that the aggregate size was too big and would not fall through/ settle between the plastic fiber optics in the mold without moving or breaking them. To remedy this issue, Quikrete grout mix (a finer cement with smaller aggregate) was used. When mixed with water, this concrete poured nicely into the molds, forming through and over the plastic fibers as it settled into place (Fig. 8).

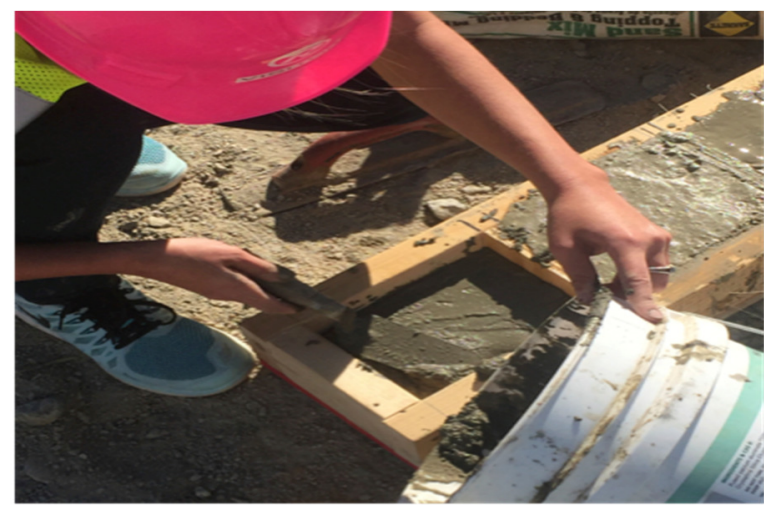

Fig. 8: Mixing the concrete and pouring it into the mold

As seen in Fig. 9, each of the four molds were filled and leveled off one at a time. When all four sections of the mold had been completed, the mold was put in a secure place for the concrete to cure (Fig. 10).

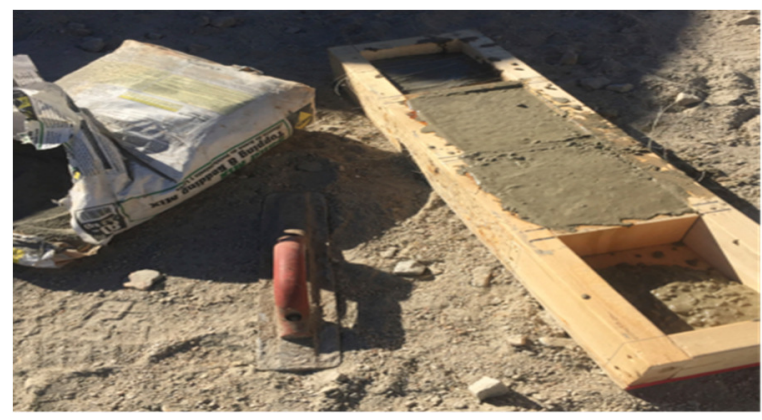

Fig. 9: All the compartments were filled to the top and levelled

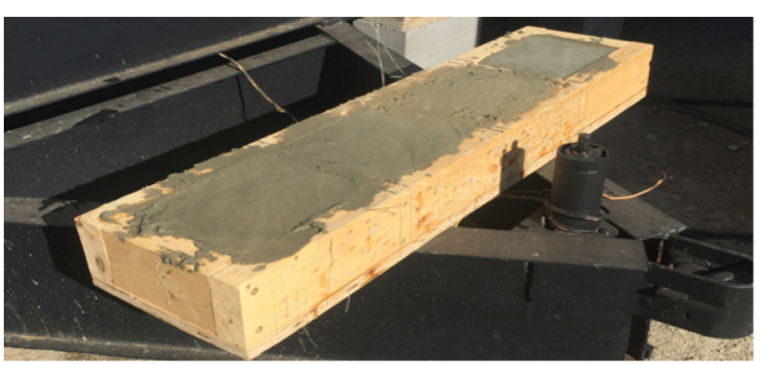

Fig. 10: Once complete, the mold was left to cure for 5 days

\subsection{Remov Mold}

After five days the concrete blocks had finished curing and the mold was ready to come off. First, the screws holding the forms together were removed, and then all excess fiber running through both sides of the mold were clipped as close to the mold as possible. Once the forms were no longer attached, they were carefully pulled from each concrete block (Fig. 11).

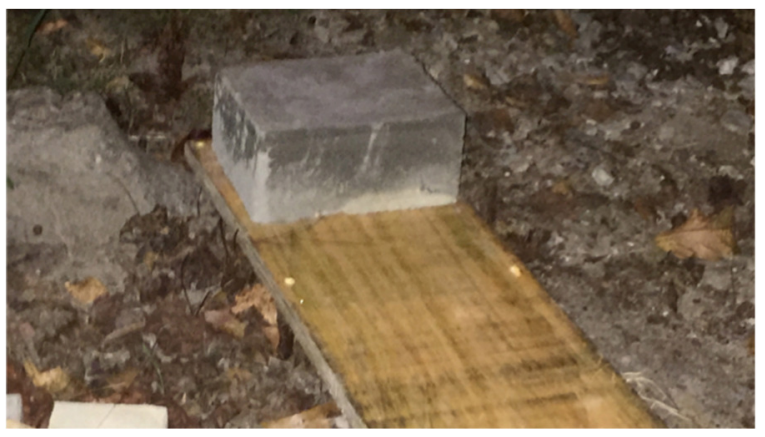

Fig. 11: The forms were removed, leaving four equal sized concrete blocks

After the blocks were free from the form, all fibers were trimmed to be flush with the sides of the blocks. Fig. 12 and 13 depict the blocks after they were removed from the forms.

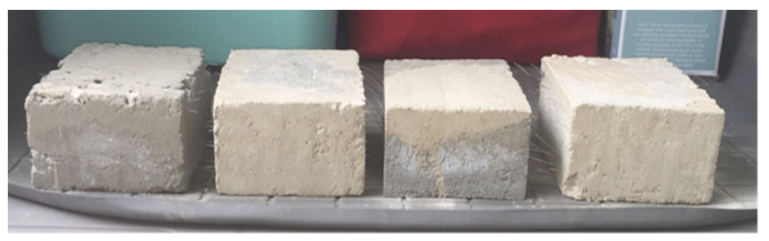

Fig. 12: Front (elevation) view of the concrete blocks after being removed from their molds 


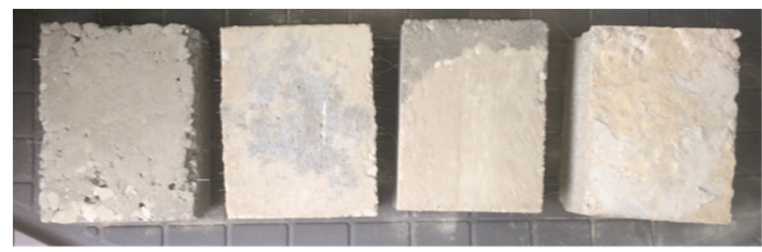

Fig. 13: Top (plan) view of the concrete blocks after being removed from their molds

\subsection{Polish Concrete Blocks}

If implemented into the industry as a building material, the light-transmitting properties of translucent concrete make it a strong candidate for the decorative concrete market. Most current applications, when used as a decorative piece (i.e. floors, bar top, furniture, interior walls, reception desks etc.), consist of some kind of polishing to give the concrete (at the very minimum) a softer, more even appearance; if not a glossy, smooth, sometimes different colored/patterned appearance. Because polishing concrete typically comes hand in hand with any 'decorative concrete' job, it was decided that these blocks would be polished just as they would in real life.

Polishing concrete requires specific equipment, knowledge, and skill that the ordinary person would not have; because of this, these blocks were taken to Precision Floor Care, a concrete polishing company located in Wetumpka, AL. In having them professionally polished (Fig. 14), it was ensured that the amount of light found to transmit through each block would be equivalent to the amount of light able to penetrate if these were used on a real project.

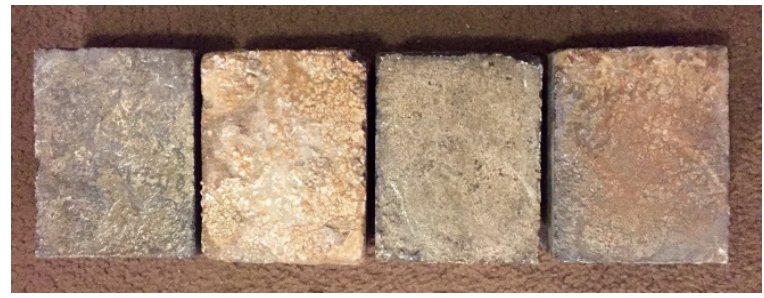

Fig. 14: Polished Concrete Blocks

Calculate the number of optic fiber strands that must pass through the surface of each block to make up $0 \%$, $5 \%, 10 \%$, and $15 \%$ Surface Volume.

-A1: 5\% - 33 Fiber Optic Strands
- A2: $10 \%$ - 47 Fiber Optic Strands

- A3: $15 \%$ - 58 Fiber Optic Strands

\subsection{Testing}

\subsubsection{Testing Means and Methods}

Like the experiment, all materials were gathered before testing commenced. Materials included the four concrete blocks, a stand, a light source (a 60 Watt, general purpose soft white halogen bulb was used), a lamp (a lamp with an adjustable arm was used to achieve the proper angle, making it possible to shine light directly onto the sides of the concrete blocks), a blackout curtain, a light meter (Ex-Tech Foot Candle Light Meter) and a pen and notebook for recording results (these can be seen in Fig. 15).

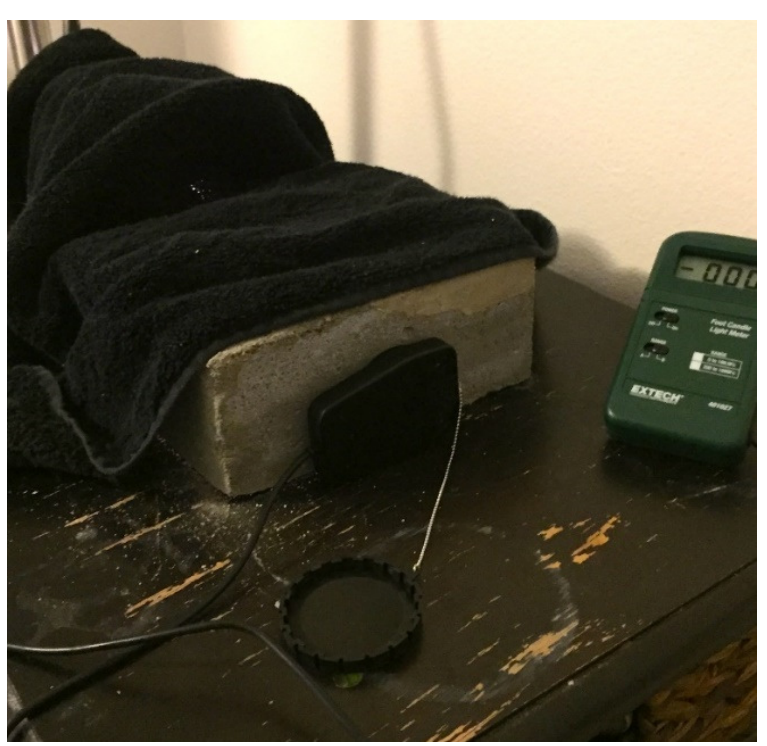

Fig. 15: Materials and Set Up used for testing

Because complete darkness was crucial in determining the exact amount of light able to travel through the fiber optics, a dark room in Dudley Hall on Auburn University's campus was utilized. Before the concrete was tested, the amount of light the light bulb gave off without any 'interruptions' was measured. This number was recorded and later used to calculate the percentage of light that successfully transferred through the fiber optics in each block.

Starting with block A, the control (or concrete block with no plastic fiber optics embedded), each block was 
placed on a stand and the blackout curtain was laid over the block, leaving one side with the fiber optics (the side the light will escape out of/ the side being tested) and draped off the back of the side the light was emitted into (Fig. 16).

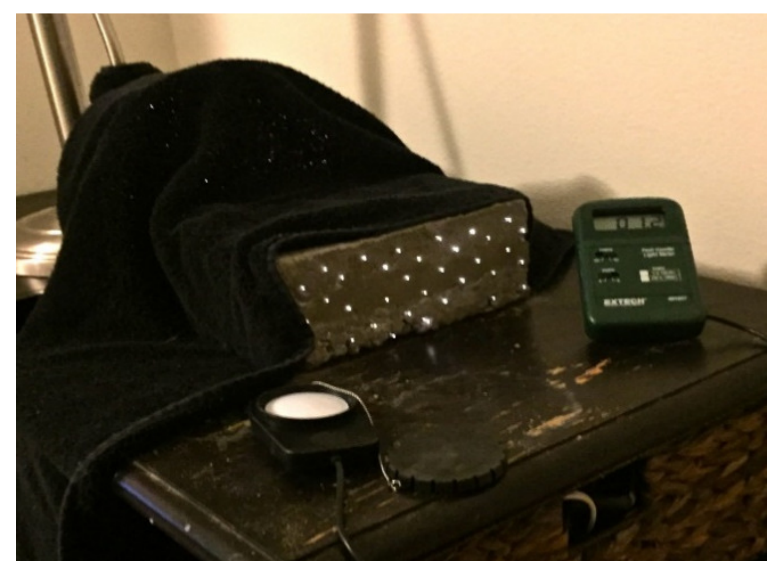

Fig. 16: Testing concrete blocks

Then, all lights were turned off and the light source was turned on and placed under the curtain, shining light directly into the back of the block (the curtain contained all light and ensured that the amount of light being read by the light meter was indeed being emitted from the concrete).

Once everything was in place and total darkness had been achieved, the light meter was turned on and held about $1 / 2$ " in front of the concrete block. Once the light meter produced a reading, it was recorded. These steps were replicated for each of the blocks until all four blocks (A, A1, A2 and A3) had been tested. To confirm all readings/measurements, the entire process was completed twice more, producing a total of three readings for each of the four blocks. All results were measured in Foot candles.

It should be noted that careful consideration ensured that everything was the same throughout each test to minimize the risk of exterior variables affecting light transmittance and skewing results. To achieve this, identical procedures were followed, meaning each block was placed in the same exact place on the table, the lamp was never moved (to guarantee it hit each block at the same spot and angle), the light meter was held in the same spot on each block at the same distance away.

Once testing was completed and all results were recorded, the data was ready to be organized and analyzed to determine how much light was able to transmit through each block of concrete.

\section{RESULTS AND ANALYSIS}

Once the polishing company returned the blocks, the concrete was ready to undergo testing. The same process was used to test each block to ensure accurate results. All findings and important information were compiled and documented. The following results were gathered upon completion of the experiment (Table 4).

\begin{tabular}{|c|c|c|c|c|}
\hline \multicolumn{5}{|c|}{ Table 4: Light Transmission Test Results } \\
\hline & $\begin{array}{c}\text { A1 } \\
(0 \%)\end{array}$ & $\begin{array}{c}\text { A2 } \\
(5 \%)\end{array}$ & $\begin{array}{c}\text { A3 } \\
(10 \%)\end{array}$ & $\begin{array}{c}\text { A3 } \\
(15 \%)\end{array}$ \\
\hline $\begin{array}{c}\text { Light } \\
\text { Source }\end{array}$ & 113.80 & 113.80 & 113.80 & 113.80 \\
\hline 1 & 0.00 & 15.60 & 34.90 & 48.70 \\
\hline 2 & 0.00 & 14.80 & 35.40 & 49.10 \\
\hline 3 & 0.00 & 15.50 & 35.20 & 48.90 \\
\hline
\end{tabular}

\subsection{Data Analysis}

To illustrate the results gathered during the experiment, all data was organized and put into graphs to show light passed through each block and trial.

The blue lines on the graph represent the direct light source. This is the result acquired from holding the light meter to the light source directly. The red lines on the graphs represent the amount of light able to pass through each block during that specific trial.

The method of analysis was chosen because it simplifies all of the data and organizes it in a way that is visually easy to understand. In paralleling the amount of light that was able to pass through the block with the total amount of light that is emitted from the light bulb, the graphs depict a simplified, comprehensible comparison of the amount of light able to transmit through the concrete. 


\subsubsection{Block A: 0\% Surface Volume}

Block A served as the control, meaning zero fiber optics were embedded into the concrete. Not only did this give the experiment a dependent variable on which to base results and comparisons, but it also ensured accurate readings when the light meter read ' 0.00 '. The results from the three tests performed on Block A are shown in Fig. 17.

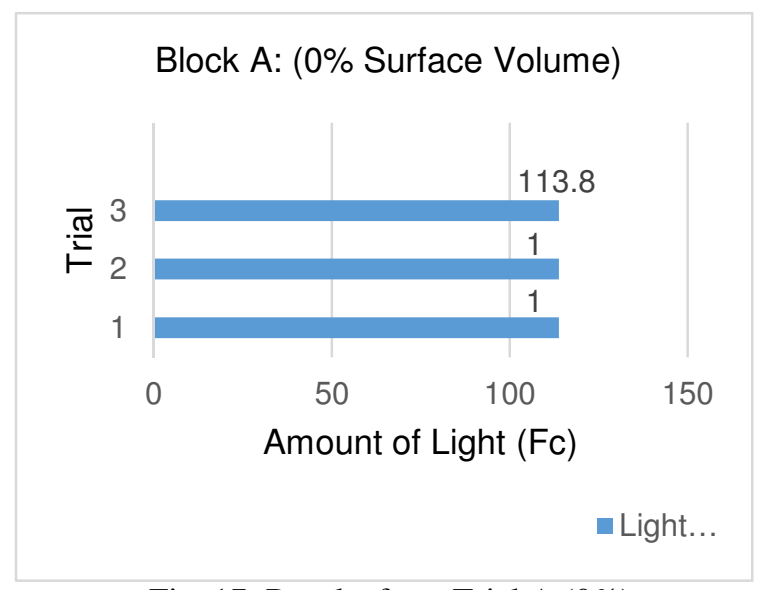

Fig. 17: Results from Trial A (0\%)

As illustrated in Fig. 17, no light was able to transmit through this block, there were zero fiber optics embedded into this block. This is important because it shows that all light read during the tests performed on block A1, A2 and A3 was transmitted through the concrete via the plastic fiber optic cables.

\subsubsection{Block A1:}

5\% Surface Volume with 5\% surface volume covered by plastic fiber optic cables, it was hypothesized that not much light would be transmitted. Regardless, it was found that on average, $14 \%$ of the light produced by the light source successfully transmitted through the concrete (Fig. 18).

\subsubsection{Block A2: 10\% Surface Volume}

The block with enough fiber optics to make up $10 \%$ of its surface volume was tested next. Because the percentage of plastic fiber optics was double for this trial, it was assumed that about twice as much light would be emitted from the face of the block A. Upon testing, it was found that the amount of light passing through the block exceeded the amount hypothesized, but not by much; with an average of $39.7 \mathrm{Fc}$, it was found that $10 \%$ surface volume equates to $35 \%$ light transmittance (Fig. 19).

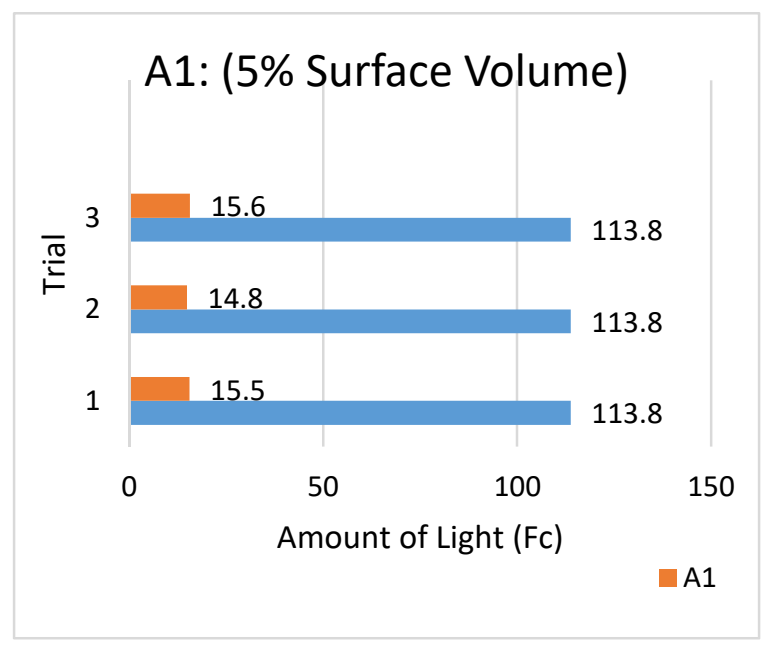

Fig. 18: Results from Tests on Block A1 (5\%)

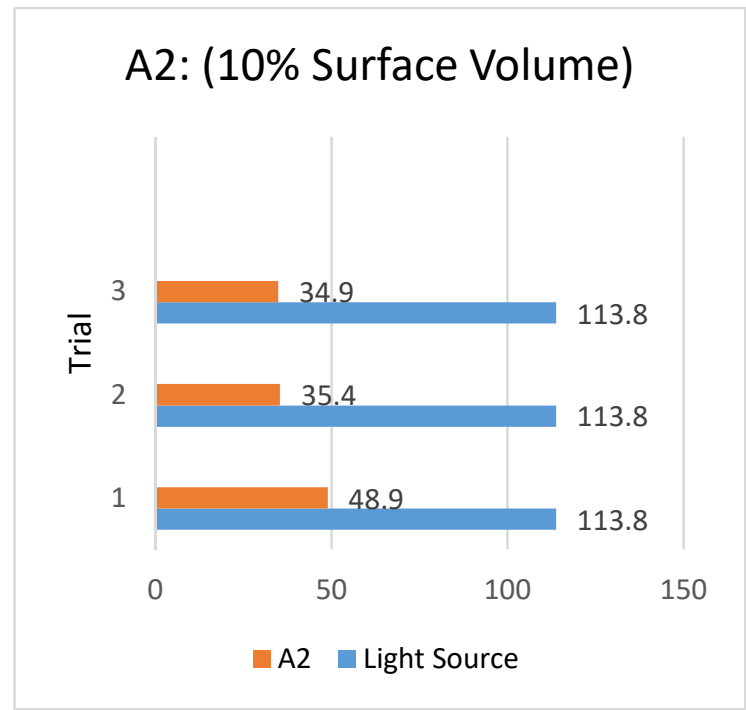

Fig. 19: Results from A2 (10\%)

\subsubsection{Block A3: 15\% Surface Volume}

The last block tested was the block with $15 \%$ of its surface volume being made up of plastic fiber optics. As seen on the graph below, the amount of light able to pass through the concrete was substantial. An average of .93 lumens emitting from the block, meaning almost $74 \%$ of the light being emitted by the light bulb was able to successfully transmit through the plastic fiber optics (Fig. 20). 


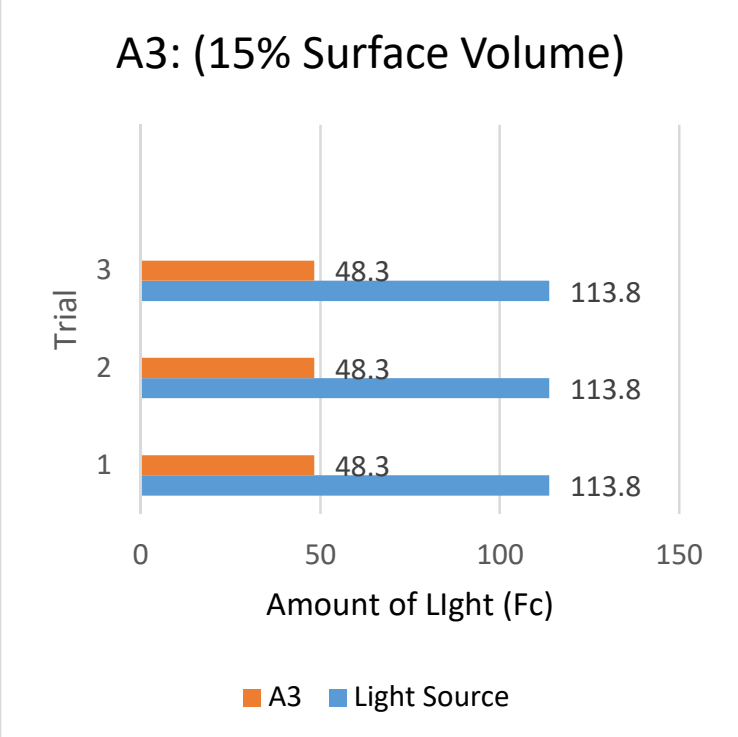

Fig. 20: Results from Trial A3 (15\%)

Average amount of Light Transmitted through each block is shown in Fig. 21.

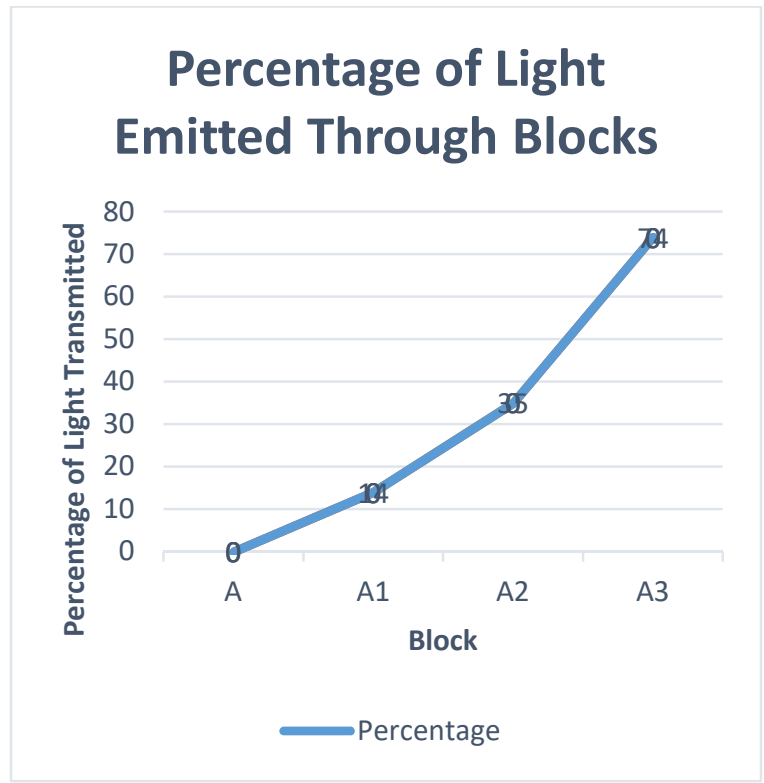

Fig. 21: Average Amount of light Transmitted through each Block

\subsubsection{Comparison of all Test Results}

In Table 5 all results are shown paralleled to illustrate the amount of light that passed through concrete and compared to the direct light source.

\begin{tabular}{|c|c|c|c|}
\hline \multicolumn{4}{|c|}{ Table 5: Comparison of all blocks and trials } \\
\hline Percentage of & \multicolumn{3}{|c|}{ Trials } \\
\cline { 2 - 4 } $\begin{array}{c}\text { Fiber Optics } \\
\text { in Concrete }\end{array}$ & $\mathbf{1}$ & $\mathbf{2}$ & $\mathbf{3}$ \\
\hline A (0\%) & 0 & 0 & 0 \\
\hline A1 (10\%) & 15.6 & 14.8 & 0 \\
\hline A2 (15\%) & 48.7 & 48.9 & 48.9 \\
\hline A3 (15\%) & 48.7 & 48.9 & 48.9 \\
\hline Light Source & 113.8 & 113.8 & 113.8 \\
\hline
\end{tabular}

\subsection{Cost Analysis}

The total cost of experimentation is $\$ 1,405.84$ for the whole project (Table 6).

\subsection{Main Findings}

The research concluded that sufficient light is able to pass through concrete through the use of plastic fiber optics. The experiment was consistent in that the number of fiber optic strands (embedded into the concrete) was directly proportionate to the amount of light transmitted through the sample. The more fiber optics, the more light transmitted. Furthermore, the research validated that natural light can be used to illuminate the inside of a building, suggesting that buildings could utilize the material and reduce the use of power supply of electricity, can be known as a green building material along with its aesthetic properties. Furthermore, it is considerable to use a fine aggregate concrete mix due to the fact that larger aggregates will break the someone fragile plastic fibers, and if broken light will not be able to pass through.

\begin{tabular}{|l|l|l|}
\hline \multicolumn{2}{|c|}{ Table 6: Cost Analysis of the Project } \\
\hline Category & \multicolumn{1}{|c|}{ Item } & \multicolumn{1}{|c|}{$\begin{array}{l}\text { Total } \\
\text { Price }\end{array}$} \\
\hline Materials & $\begin{array}{l}\text { Concrete } \\
\text { (3 bags at \$4.95 per bag) }\end{array}$ & $\$ 14.85$ \\
& $\begin{array}{l}\text { Fiber Optics } \\
\text { (50 pieces, 2 m long) }\end{array}$ & $\$ 32.99$ \\
\cline { 2 - 3 } & $\begin{array}{l}\text { Mold Materials } \\
\text { (Wood, Screws } \text { etc. })\end{array}$ & $\$ 40.00$ \\
\hline Experiment & Drills, Wood, Screws & $\$ 60.00$ \\
\hline $\begin{array}{l}\text { Labour } \\
\text { (per hour) }\end{array}$ & $\begin{array}{l}\text { 17.00/hr } \\
\text { (person 1: 30 Hours) } \\
\text { (Person 2: 44 Hours }\end{array}$ & $\$ 1,258$ \\
\hline Total & & $\$ 1,405.84$ \\
\hline
\end{tabular}




\section{CONCLUSIONS AND RECOMMENDATIONS}

\subsection{Conclusion}

Translucent concrete is an incredible concept formed with embedding plastic fiber optic strands into the concrete, this combination has numerous ways of applications. This material promotes safety, privacy and security as well as integrate the concept of green energy saving into the construction industry when used as a structural building material and ornamental.

The encouraging is that optical fibers do not allow any loss of light because of their light guiding properties. This means that once the light enters into one side of the plastic fiber optic strand, it reflects against the inside surfaces of the strand until it exits through the other side. In this way the light will transmit through the brick and be released out the opposite surface, without wastage and the thickness of concrete does not affect.

In spite of having various advantages, it is an expensive and time-consuming material to make. Due to this, translucent concrete has been used for smaller projects rather than to opt for big ones.

This study concludes that the transparency of light is possible in concrete. It has good light guiding properties and the ratio of optical fiber volume to concrete is proportionate to light transmission.

\subsection{Recommendations for Future Research}

The new innovations in translucent material has made it famous in last decade but much more is left to experiment with the property of transmitting light, but does it hold compressive and tensile strengths that are strong enough to withstand harsh climates? Can it really be used for all the potential applications discussed throughout this paper such as lit sidewalks, fire escapes, or even utilized as a 'green' or energy saving building material.

While some research, experiments, and articles have been released pertaining to these questions, most information published pertains to the lighttransmitting pr*operties of this novel material; however, with more universal research and experimentation, other properties of this material will be discovered, possibly making or breaking its introduction into the construction sector. Now the focus is being given on aesthetic properties of translucent concrete but it is recommended that more in depth research to be performed as to reach a more conclusive notion of this materials potential.

Then, its high cost can be decreased through experimentation to make it more affordable. As of now, the process is time consuming and requires man power and skill, both of which are not cost effective. While newer technologies have been put into place, where the fibers are woven into a sheet and laid between layers of concrete, it is only a step in the right direction but need more solutions.

With further research and knowledge, translucent concrete can realize its creators' visions of "cities that glow from within" as well as the building material and light source which can be used for floor, walls and for ambiance (NagDive, Shekar, 2013).

Translucent concrete is inventive stuff that has the potential to be used for a multitude of applications. The more it is used and researched; the more uses and knowledge will be procured.

\section{REFERENCES}

1. Ahuja A., Mosalam K.M., Zohdi, T. I. 2015, "Computational Modeling of Translucent Concrete Panels", Journal of Architectural Engineering, Vol. 21, Issue 2, June 2015.

2. Allen E., Iano J., "Concrete Construction, Fundamentals of Building Construction Materials and Methods", Ch. 13, pp. 515-551. Hoboken, New Jersey, John Wiley \& Sons Inc., 2009.

3. Arvaniti E.C., Juenger M.C.G., Bernal S. A., Duchesne J., Courard L., Leroy S., Provis J.L., Klemm A., De Belie N., "Determination of Particle Size, Surface Area, and Shape of Supplementary Cementitious Materials by 
Different Techniques", Materials and Structures, Vol. 48, No. 11, pp. 3687-3701. 2015.

4. Bashbash B.F., Hajrus R.M., Wafi D.F., Alqedra M.A., "Basics of Light Transmitting Concrete", Global Advanced Research Journal of Engineering”, Technology and Innovation, Vol. 2 No. 3, pp. 076-083, March 2013.

5. "Basic Structure of an Optical Fiber", Tpub, Integrated Publishings, https://www.tpub.com, Dec. 2014.

6. Bhavin K., Kashiyani B.K., Raina V., Pitroda J., Shah B.K., "A Study on Transparent Concrete: A Novel Architectural Material to Explore Construction Sector", International Journal of Engineering and Innovative Technology, Vol. 2, No. 8, February 2013.

7. Bhushan P.M.N.V., Johnson D., Pasha A.B., Prasanthi K., "Optical Fibres in the Modeling of Translucent Concrete Blocks", International Journal of Engineering Research and Applications, Vol. 3, No. 3, pp.013-017, May-Jun 2013.

8. Gawatre D., Giri S.D., Bande B.B., "Transparent concrete as an eco-friendly material for building", International Journal of Engineering Science Invention, Vol 5, No. 3, pp. 55-62, 2016.

9. Goho A., "Concrete Nation: Bright Future for Ancient Material", Science News, Vol. 167, No. 1, 2005.

10. "Light's Labour's Lost: Policies for Energy Efficient Lighting”, International Energy Agency, France, 29th June 2006. Available at https://www.iea.org/news/lights-labourslostpolicies-for-energy-efficient-lighting

11. He J., Zhou Z., Ou J, Huang M., "Study on Smart Transparent Concrete Product and Its Performances", Proceedings of the 6th International Workshop on Advanced Smart Materials and Smart Structures Technology, Dalian, China, 25-26 July, 2011.

12. Kamdi A.B., "Transparent Concrete as a Green Material for Building", International Journal of Structural and Civil Engineering Research, Vol. 2, No. 3, pp. 172-175, 2015.

13. Martinez A., "Translucent Concrete: The Path to a Brighter Future (Materials)", Design LifeCycle, 13 March 2014. Available at: http://www.designlife-

cycle.com/lighttransmitting-cement.

14. McGillivary S., "Translucent Concrete: An Emerging Material", Building and Architecture, Vol. 14, No.2, November 2014.

15. Momin A. A., Kadiranaikar R.B., Jagirdar V.S., Inamdar A.A., "Study on Light Transmittance of Concrete Using Optical Fibers and Glass Rods", IOSR Journal of Mechanical and Civil Engineering, pp. 67-72, 2014.

16. Santhakumar A.R., "Concrete Technology", Oxford Publishing Co., New Delhi, 2007.

17. Shanmugavadivu P.M., Scinduja V., Sarathivelan T., Shudesamithronn C.V., "An Experimental Study on Light Transmitting Concrete", International Journal of Research in Engineering and Technology, Vol. 3, Special Issue 11, June. 2014.

18. Nagdive N.R., Bhole S.D., “To evaluate properties o Translucent Concrete/Mortar and their Panels, International Journal of Research in Engineering and Technology, Vol.1, No.7, pp. 2330, 2013.

19. Paul S., Dutta A., "Translucent Concrete", International Journal of Scientific and Research Publications, Vol.3, No. 10, October 2013.

20. Shanmugavadivu1 P.M., Scinduja V., Sarathivelan T., Shudesamithronn C.V, "An Experimental Study on Light Transmitting Concrete", International Journal of Research in Engineering and Technology, Vol. 3, Special Vol. 11, June 2014. 